\title{
How to grow Xenopus laevis tadpole stages to adult
}

DOI:

10.1101/pdb.prot106245

\section{Document Version}

Accepted author manuscript

Link to publication record in Manchester Research Explorer

\section{Citation for published version (APA):}

Ishibashi, S., \& Amaya, E. (2020). How to grow Xenopus laevis tadpole stages to adult. Cold Spring Harbor Protocols. https://doi.org/10.1101/pdb.prot106245

\section{Published in:}

Cold Spring Harbor Protocols

\section{Citing this paper}

Please note that where the full-text provided on Manchester Research Explorer is the Author Accepted Manuscript or Proof version this may differ from the final Published version. If citing, it is advised that you check and use the publisher's definitive version.

\section{General rights}

Copyright and moral rights for the publications made accessible in the Research Explorer are retained by the authors and/or other copyright owners and it is a condition of accessing publications that users recognise and abide by the legal requirements associated with these rights.

\section{Takedown policy}

If you believe that this document breaches copyright please refer to the University of Manchester's Takedown Procedures [http://man.ac.uk/04Y6Bo] or contact uml.scholarlycommunications@manchester.ac.uk providing relevant details, so we can investigate your claim.

\section{OPEN ACCESS}


In Chapter 2. Eggs, embryos and tadpoles

\section{How to Grow Xenopus laevis Tadpole Stages to Adult}

How to grow X. laevis tadpoles to adulthood (Short title)

Shoko Ishibashi and Enrique Amaya ${ }^{1}$

Division of Cell Matrix Biology \& Regenerative Medicine

School of Biological Sciences

Faculty of Biology, Medicine and Health

University of Manchester

Manchester M13 9PT

United Kingdom

${ }^{1}$ Correspondence: enrique.amaya@manchester.ac.uk 


\section{ABSTRACT}

According to Weisz (1945), the tadpole stage can be divided into three forms, which broadly separate the tadpole stages into those occurring prior to the initiation of limb development, those covering limb development, and those encompassing metamorphosis. The 1st form corresponds to Nieuwkoop and Faber (NF, 1956) stages 45 through 47 (NF45-47) (Nieuwkoop and Faber 1994), beginning about 4 days after fertilization. Appearance of the hindlimb bud at NF48 defines the initiation of the 2nd form. This form lasts the longest (two or more months) and covers the primary growth phase of the tadpole and includes the stages when the hindlimbs and forelimbs develop (NF48-66). The 3rd form (NF59-66) features the onset and climax of metamorphosis and takes around 8 days to complete. During metamorphosis, the body undergoes dramatic changes internally and externally: culminating with the tails and gills being resorbed and the froglets starting to swim with their legs and respiring with their lungs. During this phase, the tadpole does not feed, while it changes from an herbivorous to an omnivorous diet. Maximal tadpole growth, especially during the 2nd form, is critically dependent on good husbandry practices. Here we describe a protocol for raising Xenopus laevis tadpoles through to adulthood. Each step may need to be modified depending on the aquaria used and local conditions. This protocol also may be used for raising Xenopus tropicalis tadpoles through metamorphosis, following minor modifications. 


\section{MATERIALS}

\section{Reagents}

ReptoMin (Tetra) (alternative foods, such as Nasco frog brittle, can be used)

Spirulina Powder - available widely, including health food stores

Gammarus (Tetra) - optional as supplement for young froglets

Water

For tadpoles, tap water should be left at least half a day or carbon filtered to dechlorinate prior to adding to aquaria

\section{Equipment}

Aquaria for tadpoles in static water

Minimum size of $8 \mathrm{~cm}$ height $\times 23 \mathrm{~cm} \times 15 \mathrm{~cm}$.

We use $15 \mathrm{~cm}$ height $\times 30 \mathrm{~cm} \times 23 \mathrm{~cm}$ (about 10L). It can be bigger, but should be a size that permits easy and regular cleaning.

Aquaria for frogs (2-12 months old) in recirculating system

$50 \mathrm{~cm} \times 30 \mathrm{~cm} \times 20 \mathrm{~cm}$ height $(30 \mathrm{~L})$ tank, with $\sim 15 \mathrm{~cm}$ water depth

Aquaria for frogs ( $>1$ year old) in recirculating system

$60 \mathrm{~cm} \times 40 \mathrm{~cm} \times 20 \mathrm{~cm}$ height $(48 \mathrm{~L})$ tank, with $\sim 17 \mathrm{~cm}$ water depth

Nets

Medium size $(10-13 \mathrm{~cm})$ for tadpoles and juveniles

Large size $(25-30 \mathrm{~cm})$ for adult frogs

Air pump for tadpoles (optional)

Aeration will help keeping water quality, but is unnecessary, if one changes 
water regularly.

\section{METHOD}

Raising $X$. laevis tadpoles through metamorphosis

1. Fertilized embryos at any stages cultured in petri dish can be transferred to a container with dechlorinated water at 2-3 cm depth. 30 to 50 embryos can be accommodated in $10 \mathrm{~L}$. The tanks can be kept in room temperature between $16-25^{\circ} \mathrm{C}$.

2. Add more water (5-10 $\mathrm{cm}$ depth) and start feeding as below when they reach NF45 and start swimming actively. Tadpoles at NF45 can be transferred to a tank with dechlorinated water at 5-10 $\mathrm{cm}$ depth.

\section{Feeding Procedure}

3. Suspend about $2 \mathrm{~g}$ of spirulina powder in $50 \mathrm{ml}$ water in a $50 \mathrm{ml}$ conical tube. The spirulina suspension can be stored in $4^{\circ} \mathrm{C}$ for a few weeks, but make up fresh if the suspension changes colour from green to blue, as this indicates that the spirulina has become anoxic and is no longer usable. Mix well by inversion before each use. Add 2-3 $\mathrm{ml}$ of spirulina suspension per 30 tadpoles or $4-5 \mathrm{ml}$ per 50 tadpoles daily.

Tadpoles tend to feed at the bottom of the tank. Therefore, it is best to add spirulina suspension rather than to adding spirulina powder directly to the tank as the powder tends to remain at the surface of the water. Instead the spirulina / water mixture tends to sink to the bottom of the tank where it is more readily consumed by the tadpoles.

4. Feed once in the morning, and check the water quality and excrements on the bottom of the tank in the evening or the next morning. If all the food is eaten, water will be clear and you will see green strings on the bottom of the tank, which are the tadpoles' excrement. If water is not clear, reduce the amount of food. If you do not see much excrement or the tadpoles' growth appears stunted, increase the amount of food. Daily observation and modifying the food intake accordingly is essential for 
ensuring the best husbandry conditions for optimal growth and raising of healthy tadpoles.

5. Increase the amount of food, as they grow. For example, when they reach NF50-52 (body length about 1.5-2 cm), feed 5-6 ml of the spirulina suspension per 30 tadpoles. At this stage, the maximum number of tadpoles that should be maintained in 10 liters is around $\mathbf{3 0}$ tadpoles. Thus, it may be necessary to split the tadpoles into two tanks or more tanks, or remove the smaller tadpoles to maintain no more than 30 tadpoles per tank.

6. When the fingers in their hindlimbs become apparent at around NF55, feed twice a day with an amount of 4-5 ml of spirulina suspension per 20-25 tadpoles. Make sure that the water is clear at the second feeding. If the water is not clear, skip the 2nd feeding on that day, or you may choose to reduce the amount of food for each feeding and feed it twice a day. At this stage, $20-25$ tadpoles can be accommodated in 10L.

7. When the legs are formed completely and arms become visible around NF58, increase the amount of food to $6-7 \mathrm{ml}$ for 20 tadpoles twice a day. Adjust the amount of food by checking the water clarity and excrements before and after feeding.

8. When their head start to shrink during metamorphosis, stop feeding them. Only feed the amount required for the remaining pre-metamorphosis growing tadpoles in the same tank. You can also transfer the tadpoles undergoing metamorphosis to another tank.

9. When their tails become very short (NF64-65), they can be fed with diet for frogs, such as ReptoMin broken into small pieces. 1-2 pieces of 2-3 mm ReptoMin per frog can be fed daily. Fertilized early spare pre-feeding stage embryos or unfertilized eggs can be good food for small froglets just after metamorphosis. Leave the food left in the tank so that they can feed freely, unless the water becomes very dirty.

The amount of food and tadpole density are listed on the table, however, please note that this is a just rough guide and adjustment may be required depending on local 
conditions.

Cleaning Procedure and Changing Water

10. Prepare dechlorinated water in a clean tank.

11. Transfer tadpoles using a net into the tank above.

12. Clean the tank and dry.

It is important to keep the bottom of the tank clean for efficient feeding where tadpoles can find food. In order to get rid of their excrements and keep the floor clean, the tank should be cleaned at least once a week even though the water appears clear. The frequency of cleaning should be increased depending on the density of tadpoles in the tank and frequency of feeding.

Feeding after Metamorphosis to Adulthood

13. For juvenile frogs, feed 2-3 pieces of ReptoMin broken into small pieces per frog daily. Temporarily turn off the water flow to each individual tank and feed them in the morning and in the afternoon remove any food left over in the tank and restart flow of water (restart re-circulation). If there is lots of food left over, reduce the amount of food in subsequent feedings.

14. Small froglets just after metamorphosis can be kept in a $30 \mathrm{~L}$ tank with a density of 30-40 frogs.

15. Increase the amount of food, as they grow. See the table. Remember to temporarily turn off water flow to each individual tank during each feed to ensure that food does not flow out of tanks before it can be eaten, but remember to restart flow once feeding has ended to each tank.

16. Sort frogs by their size regularly, so that all frogs in the tank are able to eat food equally without competing for food. $5-7 \mathrm{~cm}$ juveniles and $8-10 \mathrm{~cm}$ juveniles can be accommodated in a 30L with a density of 20-25 frogs and 10-15 frogs, respectively. 
48L tank can hold $20-30$ of $8-10 \mathrm{~cm}$ frogs.

17. When they reach around $10 \mathrm{~cm}$, males reach maturity and do not eat as much as females. Therefore, keep monitoring the leftover food and adjust the amount of food accordingly.

18. When they reach adulthood separate males and females (body length $12-15 \mathrm{~cm}$ for females, $\sim 10 \mathrm{~cm}$ for males). Adult frogs can be accommodated in $48 \mathrm{~L}$ tank with a density of 10 frogs for females and 15-20 frogs for males.

18. Feed adult frogs every other day. Adult frogs can be kept at $16-23^{\circ} \mathrm{C}$, however, the lower temperature of around $16-18^{\circ} \mathrm{C}$ is preferable for Xenopus laevis, as the risk for outbreak of diseases will be reduced and the females tend to lay better quality eggs when the females are maintained at lower temperatures.

Cleaning and Changing water

19. For juveniles fed daily in static water, clean the tank and change water once or twice a week, depending on their density.

20. For juveniles fed daily in the circulating system with filtered water, the tanks can be cleaned monthly.

21. For adult frogs fed every other day in the circulating system with filtered water, the tanks can be cleaned once or twice a year, depending on the system.

Adult females can be ovulated every 3 months. If egg quality is poor, you may need to increase the amount of food.

\section{TROUBLE SHOOTING}

Problem (tadpole stage): Tadpoles appear bent. 
Solution: It is caused most likely by calcium deficiency or physical damage. Therefore, feed more spirulina, or reduce the density of tadpoles in the tank. Take care when you transfer tadpoles with a net.

Problem (tadpole stage): Water becomes become putrid and tadpoles are floating or dying.

Solution: Change water immediately. This is likely the result of overfeeding. Therefore decrease the amount of food per feeding. It may also be caused by high water temperature, which encourages bacterial growth. Temperature should be kept between $16-25^{\circ} \mathrm{C}$.

\section{DISCUSSION}

The amount of food and frequency of feeding should change depending on the number of tadpoles in the tank and their age. Therefore, daily observations of water quality and tadpole health/growth are the most important things to do for raising tadpoles. One good indication for tadpole health is the colour of their blood vessels in the head. The blood vessels should appear bright red if they have enough food and oxygen. If they are pale, increase the amount of food and consider aerating the tanks. The amount and condition of excrements should also be monitored daily. If they are fed enough, you will see long green strings on the bottom of the tank. However, if there are no strings, especially if they are all fragmented, this suggests that the tadpoles are searching food and picking their excrements. Therefore, in this case, you should increase the amount of food given to the tadpoles.

If you feed tadpoles daily on weekdays, you may be able to skip feeding during the weekends, as less food is better than overfeeding, which could lead to deaths of all tadpoles. Even when you can feed them at the weekend, it may be better to feed less if you will not be able to check water quality later in that day.

\section{REFERENCES}

Nieuwkoop PD, Faber J. 1994. Normal table of Xenopus laevis (Daudin). A systematical and chronological survey of the development from the fertilized egg till the end of metamorphosis. Garland Publishing, Inc., New York. 
Weisz PB. 1945. The normal stages in the development of the South African clawed toad, Xenopus laevis. Anat Rec 93: 161-169.

TABLE

\begin{tabular}{|c|c|c|c|c|}
\hline stages & $\begin{array}{l}\text { body length or } \\
\text { features }\end{array}$ & $\begin{array}{l}\text { Max tadpole numbers for } 10 \mathrm{~L} / \\
\text { frog numbers for } 30 \text { or } 48 \mathrm{~L}\end{array}$ & amount of food per feeding & $\begin{array}{l}\text { frequency of } \\
\text { feeding }\end{array}$ \\
\hline \multirow{2}{*}{$\begin{array}{l}\text { NF45 } \\
\text { tadpoles }\end{array}$} & & 30 & 2-3 $\mathrm{ml}$ of spirulina / water mixture & once a day \\
\hline & & 50 & $4-5 \mathrm{ml}$ of spirulina / water mixture & once a day \\
\hline $\begin{array}{l}\text { NF50 } \\
\text { tadpoles }\end{array}$ & $1.5-2 \mathrm{~cm}$ & 30 & $5-6 \mathrm{ml}$ of spirulina / water mixture & once a day \\
\hline $\begin{array}{l}\text { NF55 } \\
\text { tadpoles }\end{array}$ & hindlimbs with digits & $20-25$ & 4-5 $\mathrm{ml}$ of spirulina / water mixture & twice a day \\
\hline $\begin{array}{l}\text { NF58 } \\
\text { tadpoles }\end{array}$ & developing arms & 20 & 6-7 ml of spirulina / water mixture & twice a day \\
\hline \multirow{6}{*}{$\begin{array}{l}\text { juvenile } \\
\text { froglets }\end{array}$} & after metamorphosis & $30-40 / 30 \mathrm{~L}$ & $\begin{array}{l}\text { 2-3 small pieces of a ReptoMin stick / } \\
\text { frog (optional pinch of crushed } \\
\text { Gammarus) }\end{array}$ & once a day \\
\hline & $3 \mathrm{~cm}$ & & $\begin{array}{l}2-4 \text { pieces of } 1 / 3-1 / 4 \text { cut ReptoMin stick / } \\
\text { frog }\end{array}$ & \\
\hline & $3-4 \mathrm{~cm}$ & $30 / 30 \mathrm{~L}$ & 1-1.5 of ReptoMin sticks / frog & once a day \\
\hline & $5-7 \mathrm{~cm}$ & $20-25 / 30 \mathrm{~L}$ & 2-3 of ReptoMin sticks / frog & once a day \\
\hline & $8-10 \mathrm{~cm}$ & $10-15 / 30 \mathrm{~L}, 20-30 / 48 \mathrm{~L}$ & 4-6 of ReptoMin sticks / frog & once a day \\
\hline & $10 \mathrm{~cm}<$ & $20 / 48 \mathrm{~L}$ & 4-6 of ReptoMin sticks / frog & once a day \\
\hline
\end{tabular}




\begin{tabular}{|l|l|l|l|l|}
\hline adult & females & $10 / 48 \mathrm{~L}$ & $6-10$ of ReptoMin sticks / frog & every other day \\
\hline & males & $15-20 / 48 \mathrm{~L}$ & $2-4$ of ReptoMin sticks / frog & every other day \\
\hline
\end{tabular}

